Review

\title{
Structural Features and Healthy Properties of Polysaccharides Occurring in Mushrooms
}

\author{
Ana Villares *, Laura Mateo-Vivaracho and Eva Guillamón \\ Centre for the Food Quality, National Institute for Agriculture and Food Research and Technology \\ (INIA), Campus Universitario Duques de Soria, c/José Tudela s/n, 42004, Soria, Spain; \\ E-Mails: mateo.laura@inia.es (L.M.-V.); eva@inia.es (E.G.) \\ * Author to whom correspondence should be addressed; E-Mail: villares.ana@inia.es; \\ Tel.: +34-975233204; Fax: +34-975233205.
}

Received: 19 October 2012; in revised form: 12 November 2012 / Accepted: 10 December 2012 /

Published: 18 December 2012

\begin{abstract}
Polysaccharides from mushrooms have attracted a great deal of attention due to the many healthy benefits they have demonstrated, such as immunomodulation, anticancer activity, prevention and treatment of cardiovascular diseases, antiviral and antimicrobial effects, among others. Isolation and purification of polysaccharides commonly involve several steps, and different techniques are actually available in order to increase extraction yield and purity. Studies have demonstrated that the molecular structure and arrangement significantly influence the biological activity; therefore, there is a wide range of analytical techniques for the elucidation of chemical structures. Different polysaccharides have been isolated from mushrooms, most of them consisting of $\beta$-linked glucans, such as lentinan from Lentinus edodes, pleuran from Pleurotus species, schizophyllan from Schizophyllum commune, calocyban from Calocybe indica, or ganoderan and ganopoly from Ganoderma lucidum. This article reviews the main methods of polysaccharide isolation and structural characterization, as well as some of the most important polysaccharides isolated from mushrooms and the healthy benefits they provide.
\end{abstract}

Keywords: polysaccharides; carbohydrates; mushroom; fungus; biological response modifier 


\section{Introduction}

Edible mushrooms have been traditionally appreciated due to their excellent sensory characteristics, including their unique aroma and taste. Mushrooms contain a wide range of molecules responsible for the fungal flavor comprising of volatile compounds [1] and unsaturated fatty acids, as well as amino acids [2,3]. Besides their excellent flavor, mushrooms have attracted much attention due to their proven healthy properties. Mushrooms contain low fat levels and low energy values, though they contain high amounts of proteins and essential amino acids. Furthermore, edible mushrooms can be considered as a source of dietary fiber, since the contents usually range from $4 \%$ to $55 \%$ (dried matter) [4-6].

Both cultivated and wild edible mushrooms have been a matter of research as therapeutic agents, and several bioactive substances have been identified showing health-promoting benefits [7]. Different functional compounds have been found in mushrooms, including phenolic compounds, sterols, terpenes, ceramides, etc. Among them, polysaccharides can be considered as one of the main groups of compounds occurring in mushrooms that are responsible for a great range of healthy properties. Recently, several polysaccharides from mushrooms have been isolated and characterized, such as lentinan from Lentinus edodes, pleuran from Pleurotus mushrooms, schizophyllan from Schizophyllum commune, or ganoderan and ganopoly from Ganoderma lucidum. Generally, bioactive polysaccharides from mushrooms consist of a $\beta$-linked glucose backbone displaying different patterns and degrees of branching. However, other polysaccharides formed by galactose or mannose have been also found in mushrooms, as well as heteropolysaccharides and glucan-protein complexes.

Polysaccharides from mushrooms have shown a great range of healthy properties, being the most important modulation of the immune system. Bioactive carbohydrates, including $\beta$-glucans, are usually viewed as biological response modifiers (BRM) [8]. Immunological modulation is involved in the prevention of several diseases, including cancer or pathogen infections, since the polysaccharide may enhance the immune system. The molecular mechanism of biological activity of polysaccharides may involve several pathways. Physical-chemical properties, such as molecular weight, primary structure, solution conformation, and polymer charge, among others, may play a role in determining whether and with what affinity polysaccharides bind to the receptors and show the biological activity.

This article reviews the main methods for polysaccharide extraction, isolation and purification, as well as the most important analytical techniques used for the structural characterization of the carbohydrates. In addition, some of the most important polysaccharides from mushrooms are described along with the healthy benefits they provide.

\section{Extraction of Polysaccharides}

Higher Basidiomycete mushrooms contain biologically active polysaccharides in the fruiting bodies, the cultured mycelium, and the cultured broth. The extraction yield of polysaccharides from fungal material depends not only on the sample nature, but also on different parameters, for instance, temperature, pressure, $\mathrm{pH}$ and ionic strength of the solvent, and fineness of solid particle grinding. Polysaccharides extraction is commonly performed in aqueous solvents, generally water or basic aqueous solutions. Mushroom samples are first freeze-dried, and then ground to a fine powder. 


\subsection{Conventional Extraction}

Conventional methods usually involve stirring the sample into aqueous solutions. Generally, samples are subjected to successive extractions [9]. Firstly, polysaccharide extraction is carried out with water at room temperature. After centrifugation, a clear supernatant is separated from the residue. The residue is secondly extracted with boiling water and again separated from the liquid by centrifugation. The remainder solid may be subsequently extracted with aqueous basic solutions $(\mathrm{NaOH}$ or $\mathrm{KOH}, 2 \% \mathrm{w} / \mathrm{v})$ at $100{ }^{\circ} \mathrm{C}$. Again, the residue is separated by centrifugation and the solid is discarded.

Water or basic aqueous solutions may not be strong enough for separating water-insoluble polysaccharides. For this purpose, acidic solutions may be employed. Glucans extracted with acid are typically non-branched or branched at a very low frequency. Several acids, including acetic, formic, hydrochloric, and phosphoric, have been tested for the isolation of water insoluble $\beta$ - $(1 \rightarrow 3)$-glucans from Saccharomyces cerevisiae [10]. Results showed that the primary structure, in terms of monosaccharide composition and side-chain branching, was not substantially altered, regardless of the acid employed. On the contrary, molecular mass, size, polydispersity and intrinsic viscosity of the glucan obtained were influenced by the $\mathrm{pK}_{\mathrm{a}}$ of the protic acid employed. The results suggested that the weaker the protic acid used, the greater the molecular mass and polydispersity of the glucan.

\subsection{Pressurized Water Extraction}

Sophisticated techniques, although not used extensively, may be a good strategy for isolating polysaccharides. Traditional solvent extraction techniques use large quantities of toxic organic solvents, are generally very laborious, and possess low selectivity and/or low extraction yields. Furthermore, sometimes conventional extraction can expose the extracts to excessive heat, light, and oxygen, and requires long extraction times, which may favor the activity of glucan-degrading enzymes.

Pressurized liquid extraction (PLE) is an emerging technique that presents important advantages over traditional extractions. During the extraction process, the solvents inside the PLE extraction cartridge are at high temperature and high pressure, near their supercritical region. The high temperature makes possible the high solubility and high diffusion rate while the high pressure keeps the solvent below its boiling point. PLE uses less solvent quantities in a shorter period of time since at high pressures and high temperatures the solvents penetrate the solid samples at a much higher rate permitting a fast and efficient extraction process with minimal solvent usage. Furthermore, PLE is automated, and involves retaining the sample in an oxygen and light-free environment. In this field, water has been employed to isolate polysaccharides from Lentinus edodes. Several pressures and times of extraction were tested in order to optimize the extraction conditions. When time was increased from 10 to $70 \mathrm{~min}$, the polysaccharide recovery increased from $80.6 \%$ to $88.6 \%$. Further increases in time did not improve the yield. In regards to pressure of extraction, the greater the pressure, the higher the yield until 15.2 $\mathrm{MPa}$, where it no longer produces an increase in polysaccharide recovery. Therefore, a pressure of $10.1 \mathrm{MPa}$ for $70 \mathrm{~min}$ at $28^{\circ} \mathrm{C}$ seem to be the optimal conditions to increase polysaccharide recovery for the isolation of $\alpha-(1 \rightarrow 4)$ and $\beta-(1 \rightarrow 6)$ glucans [11]. Depending on the polysaccharide structure and source, extraction operating conditions may vary. For instance, other 
authors have described the isolation of $\beta$ - $(1 \rightarrow 3)$-glucans from seaweeds. In this case, pressurized water extraction operated at $150{ }^{\circ} \mathrm{C}$ for $20 \mathrm{~min}$ and the recovery was $13.8 \%$ [12].

\subsection{Supercritical Fluid Extraction}

Supercritical fluid extraction (SFE) has been previously used for the extraction of bioactive compounds [13]. SFE consists of the extraction by using a solvent at a temperature and a pressure above its supercritical point. Near to the critical point, small changes in pressure or temperature result in large changes in density, which allows for the control of many properties of the supercritical fluid. Carbon dioxide is commonly used as a solvent since $\mathrm{CO}_{2}$ is environmentally friendly, has a relatively high liquid-like density, low viscosity and high diffusivity. These properties provide a very special solvent that is effective both at dissolving materials and penetrating solid matrices. During supercritical carbon dioxide $\left(\mathrm{SC}-\mathrm{CO}_{2}\right)$ extraction, the temperature is relatively low and organic solvents are excluded, so decomposition of the active components is avoided. In addition, during the dynamic process, fresh supercritical $\mathrm{CO}_{2}$ flows through materials continuously and the mass transfer is intensive, which may result in a satisfactory performance.

Process parameters, including operating pressure, temperature, time and $\mathrm{CO}_{2}$ flow rate, must be investigated for the optimization of the $\mathrm{SC}-\mathrm{CO}_{2}$ conditions. This technique was used to isolate carbohydrates from Ganoderma lucidum. When the flow rate was between 4 and $10 \mathrm{~kg} / \mathrm{h}$, the polysaccharide recoveries increased with the $\mathrm{CO}_{2}$ flow rate; however, when it exceeded $10 \mathrm{~kg} / \mathrm{h}$, the yields did not increase much further. The polysaccharide recoveries increased when the operating pressure changed from 27 to $35 \mathrm{MPa}$. Differently, the effect of temperature was influenced by the operating pressure. Thus, at low pressures, the higher the temperature, the greater the polysaccharide recovery. In contrast, at high pressures, the effect of the temperature $\left(25-35^{\circ} \mathrm{C}\right)$ was not substantial. Regarding extraction time, the recovery increased with time $(4 \mathrm{~h})$. Therefore, the optimum conditions for the extraction of polysaccharides from Ganoderma lucidum were pressure $35 \mathrm{MPa}$, temperature $25^{\circ} \mathrm{C}$, time $4 \mathrm{~h}$ and $\mathrm{CO}_{2}$ flow rate $10 \mathrm{~kg} / \mathrm{h}[14]$.

\subsection{Ultrasound-Assisted Extraction}

Ultrasonic-assisted extraction (UAE) is an expeditious, inexpensive and efficient alternative to traditional extraction techniques and, in some cases, even to supercritical fluid and microwave-assisted extraction. The sound waves propagate into the extraction solvent and result in alternating high-pressure (compression) and low-pressure (rarefaction) cycles. During the low-pressure cycle, high-intensity ultrasonic waves create vacuum bubbles in the solvent, and when the bubbles attain a volume at which they can no longer absorb energy, they collapse violently during the high-pressure cycle so as to disrupt molecular interactions and favor extraction. This technique has been widely used in the fractionation of plant materials [15]. Operating parameters (ultrasonic power, ratio of water to sample, extraction time and extraction temperature) must be optimized to increase polysaccharide recovery. For instance, for the separation of polysaccharides from black fungus, the operating extraction conditions were ultrasonic power $350 \mathrm{~W}$, a ratio of water to sample 5, and $35 \mathrm{~min}$ of extraction time at $90{ }^{\circ} \mathrm{C}$ [16]. Polysaccharides from Agaricus bisporus mushrooms were extracted at 
the following conditions: ultrasonic power $230 \mathrm{~W}$, at $70{ }^{\circ} \mathrm{C}$ for $62 \mathrm{~min}$, and a ratio of water volume to raw material weight of $30 \mathrm{~mL} / \mathrm{g}$, achieving a yield of $6.02 \%$ [17].

\subsection{Microwave-Assisted Extraction}

Microwave-assisted extraction (MAE) is an alternative approach to the traditional extraction methods. This technique, widely used in the extraction of bioactive compounds, provides a rapid sample preparation with reduced amounts of solvent. Microwaves heat up the molecules by ionic conduction and dipole rotation. If the extraction medium offers a resistance to the ion migration, a friction is generated and the minute microscopic traces of moisture occurring in the sample are heated. This process generates tremendous pressure on the cell wall until rupture and release of active compounds from the sample. Microwaves have been employed for the extraction of polysaccharides from Agaricus blazei Murrill [18]. The optimum conditions for a $12.35 \%$ recovery were extraction time $29.37 \mathrm{~min}$, microwave power $400 \mathrm{~W}$, extraction temperature $74.64{ }^{\circ} \mathrm{C}$ and ratio of water to material 32.7:1. In the case of Cordyceps militaris, the optimal conditions to obtain the highest polysaccharide yield were a microwave power of $744.8 \mathrm{~W}$ for $4.2 \mathrm{~min}$ and a ratio of solution to solid of $31.1 \mathrm{~mL} / \mathrm{g}$ [19]. Similarly, three polysaccharide fractions were separated from Lycoris aurea [20].

The microwaves technique can be hyphenated with ultrasound-assisted extraction in order to reduce extraction time, increase efficiency and save energy. The experimental results confirm that ultrasonic/microwave assisted extraction (UMAE) of polysaccharides had great potential and efficiency compared with traditional hot water extraction. This coupled method was employed for the separation of polysaccharides from Lycium barbarum at the following optimized operating conditions: microwave power of $500 \mathrm{~W}$ for $10 \mathrm{~min}$ and ultrasonication for $30 \mathrm{~min}$ at $50{ }^{\circ} \mathrm{C}$ and $\mathrm{pH} 9.0$ [21]. In the case of polysaccharides from Ganoderma lucidum, the optimal extraction conditions were ultrasonic power of $50 \mathrm{~W}$, microwave power of $284 \mathrm{~W}$, extraction time of $701 \mathrm{~s}$ and water/solid ratio of 11.6:1, respectively [22]. Using this coupled method, the yield of polysaccharides could be significantly improved compared with that of classical hot water extraction, reaching nearly $100 \%$ yield, and increased by $27.7 \%$ as against ultrasound-assisted extraction. Polysaccharides were also separated from Inonotus obliquus by microwave and ultrasound-assisted extraction at $90 \mathrm{~W}$ microwave power with $40 \mathrm{kHz}$ ultrasonic frequency, and solid/water ratio was 1:20 (w/v) for $19 \mathrm{~min}$ [23]. Under these conditions, the recovery and purity of polysaccharides were $3.25 \%$ and $73.16 \%$, respectively, which are above those of traditional hot water extraction.

\section{Purification}

Polysaccharides extracted from the source material are generally dissolved in water or aqueous solutions. Nevertheless, other macromolecules, such as proteins, may be also present in the medium. Therefore, several purification steps must be carried out to remove other substances. The samples may be subjected to a previous step consisting of a methanolic extraction in order to remove phenolic compounds, monosaccharides, amino acids and other related molecules. The elimination of phenolic derivatives is successful [24], and increases the effectiveness of extraction [25]. Proteins can be removed by precipitation with trifluoroacetic acid $(20 \%, \mathrm{w} / \mathrm{v})$ or by treatment with the enzyme protease at $40{ }^{\circ} \mathrm{C}$ for $1 \mathrm{~h}(\mathrm{pH} 7.5)$. Then, proteins are separated by centrifugation. 
After protein removal, polysaccharides are precipitated from the supernatants by the addition of ethanol in 2:1 ratio $(\mathrm{v} / \mathrm{v})$. Concentrated sodium chloride solutions can be added to favor the precipitation, and the solid can be washed with organic solvents, such as acetone or ethanol.

Once polysaccharides have been separated from other compounds, pure carbohydrate fractions are obtained; however, each fraction may contain several polysaccharides showing different molecular sizes. Fractionation can be performed by precipitation with ammonium sulfate. This method has been employed for polysaccharides from cereals and the dominant mechanism of fractionation is the molecular size [26,27].

Size exclusion chromatography (SEC) allows the separation of polysaccharides according to their size, and the subsequent determination of the molecular weight. Columns composed of hydroxylated polymers with residual carboxyl functionality are usually employed for the separation of polysaccharides. Elution is performed with diluted $\mathrm{NaCl}, \mathrm{NaNO}_{3}$ or $\mathrm{NaH}_{2} \mathrm{PO}_{4}$ solutions at low flow rates. Polysaccharide detection is achieved by refractive index detectors or by postcolumn derivatization with calcofluor $[28,29]$.

\section{Available Techniques for Structural Elucidation}

Structural analysis of polysaccharides requires the determination of molecular mass, chain composition, configuration and conformational isomers, sequence of monosaccharide residues, presence and position of branches and functional groups, and presence of interglycosidic linkages. Nowadays, there is a wide range of characterization techniques available to obtain structural details of polysaccharides. Chemical methods involve the use of reactions to get more insight into the chemical structure and arrangement. In contrast, analytical techniques are gaining more importance since sample preparation is straightforward and they give precise information.

\subsection{Chain Composition of Monosaccharides}

Monosaccharide composition is usually studied by the acid hydrolysis of the polysaccharides and the subsequent analysis of the resultant monosaccharides. Hydrolysis is usually performed with trifluoroacetic acid (TFA) at temperatures up to $120^{\circ} \mathrm{C}$. Other acids, such as $\mathrm{H}_{2} \mathrm{SO}_{4}$ or $\mathrm{HCl}$, could also be employed [30].

Monosaccharide profile can be determined by high performance liquid chromatography (HPLC) or, after derivatization, by gas chromatography. Gas chromatography of alditol acetates is widely used for the identification and quantification of sugars forming the chain. Monosaccharides are first reduced to their corresponding alditols with sodium borohydride and then they are acetylated. Separation is usually achieved in polar stationary phases [31].

\subsection{Presence and Position of Branches}

$O$-methylation of polysaccharides is an important sample preparation step in structural analysis of complex carbohydrates. Other derivatives, such as trimethylsilyl, acetyl, trifluoroacetyl, methaneboronate, acetal, or a combination of them, can also be employed; however, $O$-methylated carbohydrates have been widely studied since the reaction confers to the structural analysis several 
advantages in the determination of the monosaccharide composition, the sequence of monosaccharide residues, and the position of branches. The permethylated carbohydrates are acid hydrolized to partially methylated monosaccharides and reduced to their corresponding alditols. The newly formed hydroxyl groups are acetylated to partially methylated and acetylated alditols, which are identified and quantified by gas chromatography coupled to mass spectrometry (GC-MS) [32]. MS is an indispensable technique that requires sample amounts in the range of picograms or less and not a high purity of polysaccharides. Although structural analysis by MS can be performed on many underivatized olygosaccharides and glycoconjugates, $O$-methylated polysaccharides are still preferred in order to increase the stability of ions and sensitivity of MS detection. Gas chromatography coupled to mass spectrometry provides useful information regarding the position of glycosidic linkage, the occurrence of branches, and monosaccharide composition in complex carbohydrates. Nevertheless, the MS analysis itself does not provide complete information about anomeric configuration, ring form and conformational isomers [33].

Nuclear magnetic resonance (NMR) can theoretically perform almost full structural analysis of underivatized complex carbohydrates. Nevertheless, the technique has some limits in its applicability. The major weakness of NMR spectroscopy as a method for structure determination is its poor sensitivity. Great sample amounts are usually required, and sample material should be homogeneous to avoid ambiguous assignments. NMR may provide information about pattern of branching; however, the interpretation of NMR data is limited by the complexity of the spectra obtained.

\subsection{Configuration of the Glycosidic Bond}

Polysaccharides occur in nature both in $\alpha$ and $\beta$ configurations; however, the physiological properties are substantially different depending on the linkage type. Therefore, the elucidation of bond configuration is an important matter of research in the structural study of polysaccharides. NMR is a powerful tool for obtaining information about the monosaccharide composition and anomeric configuration. Comparison of chemical shifts and coupling constants with spectral data found in the literature for related polysaccharides provides relevant information about the anomeric configuration. At the ${ }^{1} \mathrm{H}-\mathrm{NMR}$ spectrum, the anomeric protons resonate at the region 4.3-5.9 ppm. If the configuration is $\alpha$, the chemical shift is larger than $\beta$ [34]. Furthermore, the $\alpha$ anomeric configuration shows ${ }^{3} J_{1,2}$ coupling constants of less than $4 \mathrm{~Hz}$ whereas $\beta$ configuration presents coupling constants greater than $7.5 \mathrm{~Hz}$ [35]. Anomeric carbon signals resonate between 90 and $112 \mathrm{ppm}$ at ${ }^{13} \mathrm{C}-\mathrm{NMR}$ experiments. Similarly to ${ }^{1} \mathrm{H}-\mathrm{NMR}$ chemical shifts, $\alpha$ anomers appear at $2-7 \mathrm{ppm}$ higher field relative to the $\beta$ anomer.

Infrared spectroscopy (IR) also provides information of anomeric configuration. For instance, the IR band at $850 \mathrm{~cm}^{-1}$ suggests an $\alpha$ configuration of the glucosyl motif [36] whereas higher frequencies $\left(890 \mathrm{~cm}^{-1}\right)$ are due to a $\beta$ anomeric configuration [37].

Anomeric configuration can also be elucidated by chemical procedures. In this field, calcofluor has been found to be a useful and rapid chemofluorescent stain for detection of $\beta$ configuration in polysaccharides. Calcofluor white, namely cellufluor, binds nonspecifically to $\beta$-linked polysaccharides and the sample fluoresces an intense green whereas $\alpha$ configurations do not exhibit fluorescence [38]. 


\subsection{Conformational Arrangement}

Methods such as ${ }^{13} \mathrm{C}-\mathrm{NMR}$ spectroscopy [39], multi-angle laser light scattering [40] or x-ray crystallography [41] have been previously used for the study of the tertiary structure of polysaccharides; however, sometimes their use is limited by availability, cost, and efficacy for evaluating carbohydrate structure in solution.

2D NMR spectroscopy provides valuable structural information related to sugar attachment sites [42]. Several techniques are available, for instance, Correlated Spectroscopy (COSY), Rotating frame Overhauser Enhancement Spectroscopy (ROESY), Nuclear Overhauser Effect Spectroscopy (NOESY), Heteronuclear Multiple Quantum Coherence (HMQC), or Heteronuclear Multiple Bond Coherence (HMBC), among others. These techniques give more insight into the correlation between atoms, which could help to elucidate the connectivities and dispositions of sugars.

Depending on their branching pattern, $\beta$-linked polysaccharides would arrange according to three main conformations: single helix, triple helix or random coil. These conformations are known to be related in an interconvertable manner in aqueous solution under certain physical and chemical treatments [43]. Chemical dyes specifically interact with certain conformations; therefore, complexation of polysaccharides with these dyes is a good strategy to get information about the polysaccharide conformation. For instance, single helix conformations are commonly found in $\beta$ - $(1 \rightarrow 3)$-linked polysaccharides. The presence of a single helix conformation may be detected by reaction with aniline blue in solution [44]. Glucans with high degrees of $\beta$ - $(1 \rightarrow 6)$-glycosidic bonds usually arrange into a triple helix. Polysaccharides showing a triple helix conformation form a complex with Congo red in alkaline solutions, which is stabilized by strong hydrogen bonds and/or hydrophobic interactions between the polysaccharide and the dye molecule. Complexation is characterized by the red shift of the absorption maximum of the Congo red solutions (489 nm) to longer wavelengths up to $520 \mathrm{~nm}[45]$.

\section{Structural Features of Polysaccharides Occurring in Mushrooms}

Bioactive polysaccharides have been isolated from several plant materials including yeasts and bacteria; in this field, the fungal kingdom was demonstrated as being a good source of bioactive carbohydrates. Among medicinal mushrooms, a polysaccharide isolated from Geastrum saccatum, consisting of a $\beta$-linked glucopyranosyl residue attached to a protein, has shown both antioxidant and anti-inflammatory activities [46]. Other mushrooms, such as Flammulina velutipes, contain complex carbohydrates. This fungus showed a polysaccharide composed of a 6-O-substituted galactopyranosyl main chain, partially substituted at $O-2$ by $3-O$-D-mannopyranosyl-L-fucopyranosyl, $\alpha$-D-mannopyranosyl, and, in a minor proportion, $\alpha$-L-fucopyranosyl groups [47]. The moiety $(1 \rightarrow 3),(1 \rightarrow 6)$-linked D-glucose has been found in several fungi. The polysaccharides have been fully characterized and some of them even have a descriptive name. For instance, the $(1 \rightarrow 3),(1 \rightarrow 6)$-glucan isolated from Schizophyllum commune is termed schizophyllan [48]. Other mushrooms, such as Sparassis crispa, Phellinus linteus [25], and some of the genus Termitomyces [49,50], have also shown to possess $\beta$-D-glucans with different linkage patterns, depending on the fungal species. 
Edible mushrooms could represent an excellent source of bioactive carbohydrates since they can be easily included in the diet, thus avoiding the isolation and purification processes required for the inedible species. In this field, a $\beta$ - $(1 \rightarrow 3)$-linked D-glucan with single unit glucosyl branches attached at $O-6$ of every third backbone residue has been isolated from Hericium erinaceus [51].

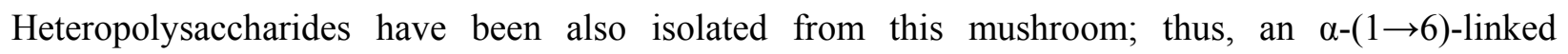
D-galactopyranosyl with rhamnose and glucose branches at $O-2$ has been described [52]. A linear water-insoluble $\beta-(1 \rightarrow 3)$-D-glucan have been extracted from the fruit body of Ganoderma lucidum [53], as well as a water-soluble $(1 \rightarrow 6)$-linked glucan with $(1 \rightarrow 4)$ branches at $O-4$ [54], or a heteropolysaccharide composed of 1,4-linked $\alpha$-D-glucopyranosyl and 1,6-linked $\beta$-D-galactopyranosyl residues with branches at $O-6$ of glucose and $O-2$ of galactose residues [55]. More complex structures showing antioxidant properties, such as a protein-bound polysaccharide has been also isolated from the genus Ganoderma, specifically from Ganoderma atrum [56]. A water-soluble neutral polysaccharide was extracted from Auricularia auricula-judae consisting of a $\beta-(1 \rightarrow 3)$-D-glucan with two $\beta$ - $(1 \rightarrow 6)$-D-glucosyl residues for every three main chain glucose residues, showing a comb-branched structure [57].

The genus Agaricus has been widely studied. Hence, several polysaccharides have been found in the cell walls of Agaricus bisporus. The fractions contained the mucilage fraction composed of glucose and galactose, a second fraction with a xylomannan associated with the glucan and several fractions of glucans showing different attachment sites [32]. The Agaricus bitorquis mushrooms contained a water-soluble $\beta$ - $(1 \rightarrow 3)$-linked glucan [58], and a glucan-protein complex was isolated from Agaricus blazei mushrooms by extraction with water at $100{ }^{\circ} \mathrm{C}$ for $5 \mathrm{~h}$. The glucan moieties showed both $\alpha$ and $\beta$ linkages, being the $\beta$ the more abundant [59].

Similarly, Lentinus edodes has attracted much interest. Besides lentinan, which is a $(1 \rightarrow 3),(1 \rightarrow 6)$-linked D-polysaccharide [60], a heteropolysaccharide consisting of a fucomannogalactan with a main chain of $(1 \rightarrow 6)$-linked $\alpha$-D-galactopyranosyl units branched at $O-2$ has been extracted [61], as well as a glucogalactan bound by $(1 \rightarrow 3),(1 \rightarrow 4)$ linkages [62].

The genus Pleurotus has been also investigated; for instance, pleuran, isolated from Pleurotus ostreatus consists of a backbone of $(1 \rightarrow 3)$-linked D-glucan every fourth residue, being substituted at $O-6$ with single D-glucopyranosyl groups [63]. The occurrence of different structural patterns between polysaccharides from Pleurotus species has been previously observed, for instance, a linear $\alpha-(1 \rightarrow 3)$-linked D-glucan has been isolated from $P$. ostreatus and P. eryngii [64], and a $\beta$-( $(1 \rightarrow 3),(1 \rightarrow 6)$-linked glucan has been extracted from $P$. ostreatus [65]. Furthermore, the mushroom Pleurotus florida has shown different types of glucans, which are a water-soluble $\alpha \beta$-polysaccharide consisting of a main chain of $\alpha-(1 \rightarrow 3)$-linked D-glucan partially substituted at $O-3$ and $O-6$ by $\beta$-D-glucose [66] and a water-insoluble $(1 \rightarrow 3),(1 \rightarrow 6)$-linked $\beta$-D-glucan [67]. Complex carbohydrates have been found in the genus Pleurotus, for instance, a 3-O-methylated $\alpha$-galactan [68], and a partially 3-O-methylated $\alpha$ - $(1 \rightarrow 4)$-linked D-galactan and D-mannan [69].

Polysaccharides from Calocybe indica have received attention due to their immunoenhancing properties. Homopolysaccharides composed of glucose have been isolated from this mushroom, for instance a water-soluble $\alpha \beta-(1 \rightarrow 4),(1 \rightarrow 6)$-glucan [70], and a water-insoluble $\beta-(1 \rightarrow 3),(1 \rightarrow 4)$-glucan (termed calocyban) [71]. Mixed polysaccharides were also found in this mushroom and the structural 
analysis revealed that they were composed of $\alpha-(1 \rightarrow 3)$-linked galactose, $\beta-(1 \rightarrow 4),(1 \rightarrow 6)$-linked glucose and fucose branches [72].

Among the wild mushrooms, some fungi, such as Boletus erythropus, have also shown water-soluble $\beta$-glucans [73]. The structural elucidation showed that the polysaccharides are composed of $(1 \rightarrow 3)$-linked glucose units with branches at $O-6$.

Table 1 reviews the main important structural features of polysaccharides isolated from mushrooms.

Table 1. Structural features of polysaccharides isolated from mushrooms.

\begin{tabular}{|c|c|c|c|}
\hline Mushroom & Type of polysaccharide & Structural features & Ref. \\
\hline Agaricus bisporus & Heteropolysaccharide & $\begin{array}{l}\text { Mucilage composed of glucose and } \\
\text { galactose }\end{array}$ & {$[32]$} \\
\hline Agaricus bisporus & Heteropolysaccharide & Xylomannan & {$[32]$} \\
\hline Agaricus bitorquis & Homopolysaccharide & $\beta$-(1 $\rightarrow 3)$-linked glucan & {$[58]$} \\
\hline Agaricus blazei & Glucan-Protein complex & $\alpha \beta$-glucan & [59] \\
\hline $\begin{array}{l}\text { Auricularia } \\
\text { auricula-judae }\end{array}$ & Homopolysaccharide & $\beta$-( $(1 \rightarrow 3)$-D-glucan with branches at $(1 \rightarrow 6)$ & {$[57]$} \\
\hline Boletus erythropus & Homopolysaccharide & $(1 \rightarrow 3)$-linked glucose with branches at $O-6$ & [73] \\
\hline Calocybe indica & Homopolysaccharide & $\alpha \beta$ - $(1 \rightarrow 4),(1 \rightarrow 6)$-glucan & {$[70]$} \\
\hline Calocybe indica & Homopolysaccharide & $\begin{array}{c}\beta-(1 \rightarrow 3),(1 \rightarrow 4) \text {-glucan } \\
\alpha-(1 \rightarrow 3) \text {-linked galactose, with }\end{array}$ & [71] \\
\hline Calocybe indica & Heteropolysaccharide & $\begin{array}{l}\beta-(1 \rightarrow 4),(1 \rightarrow 6) \text {-glucose } \\
\quad \text { and fucose branches }\end{array}$ & {$[72]$} \\
\hline Flammulina velutipes & Heteropolysaccharide & $\begin{array}{c}\text { 6-O-galactopyranoses substituted at } O-2 \text { by } \\
\text { 3-O-D-mannopyranosyl-L-fucopyranosyl, } \\
\alpha \text {-D-mannopyranosyl, and } \\
\alpha \text {-L-fucopyranosyl }\end{array}$ & {$[47]$} \\
\hline Ganoderma atrum & Protein-glucan complex & $\beta$-linked mannose, galactose and glucose & {$[56]$} \\
\hline Ganoderma lucidum & Homopolysaccharide & $\beta$ - $(1 \rightarrow 3)$-linked D-glucan & {$[53]$} \\
\hline Ganoderma lucidum & Homopolysaccharide & $\begin{array}{c}(1 \rightarrow 6) \text {-glucan with }(1 \rightarrow 4) \text { branches at } O-4 \\
\alpha-(1 \rightarrow 4) \text {-D-glucopyranosyl and }\end{array}$ & {$[54]$} \\
\hline Ganoderma lucidum & Heterolpolysaccharide & $\begin{array}{l}\beta-(1 \rightarrow 6) \text {-D-galactopyranosyl with branches } \\
\text { at } O-6 \text { of glucose and } O-2 \text { of galactose }\end{array}$ & {$[55]$} \\
\hline Geastrum saccatum & Glucan-Protein complex & $\beta$-linked glucan & {$[46]$} \\
\hline Hericium erinaceus & Homopolysaccharide & $\beta-(1 \rightarrow 3)$-D-glucan with branches at $O-6$ & {$[51]$} \\
\hline Hericium erinaceus & Heterolpolysaccharide & $\begin{array}{l}\alpha-(1 \rightarrow 6) \text {-D-galactopyranosyl with rhamnose } \\
\text { and glucose branches at } O-2\end{array}$ & {$[52]$} \\
\hline Lentinus edodes & Homopolysaccharide & $(1 \rightarrow 3),(1 \rightarrow 6)$-D-polysaccharide & {$[60]$} \\
\hline Lentinus edodes & Heteropolysaccharide & $\begin{array}{l}\text { Fucomannogalactan of }(1 \rightarrow 6) \text {-linked } \\
\alpha \text {-D-galactopyranoses branched at } O-2\end{array}$ & {$[61]$} \\
\hline Phellinus linteus & Homopolysaccharide & $\beta$ - $(1 \rightarrow 3)$-linked D-glucan & {$[25]$} \\
\hline Pleurotus eryngii & Homopolysaccharide & $\alpha-(1 \rightarrow 3)$-linked D-glucan & [64] \\
\hline Pleurotus florida & Homopolysaccharide & $\begin{array}{c}\alpha-(1 \rightarrow 3)-\mathrm{D}-\text { glucan branched at } O-3 \text { and } O-6 \\
\text { by } \beta \text {-D-glucose }\end{array}$ & {$[66]$} \\
\hline Pleurotus florida & Homopolysaccharide & $\beta$ - $(1 \rightarrow 3),(1 \rightarrow 6)-$-D-glucan & [67] \\
\hline Pleurotus ostreatus & Homopolysaccharide & $(1 \rightarrow 3),(1 \rightarrow 6)$-D-polysaccharide & [63] \\
\hline Pleurotus ostreatus & Homopolysaccharide & $\alpha-(1 \rightarrow 3)$-D-glucan & [64] \\
\hline
\end{tabular}


Table 1. Cont.

\begin{tabular}{cccc}
\hline Mushroom & Type of polysaccharide & Structural features & Ref. \\
\hline Schizophyllum commune & Homopolysaccharide & $(1 \rightarrow 3),(1 \rightarrow 6)$-D-glucan & {$[48]$} \\
Sparasis crispa & Homopolysaccharide & $\beta-(1 \rightarrow 3)$-D-glucan & {$[25]$} \\
Termitomyces eurhizus & Homopolysaccharide & $\beta-(1 \rightarrow 3)$-D-glucan & {$[49]$} \\
Termitomyces & Homopolysaccharide & $\beta-\mathrm{D}$-glucan & {$[50]$} \\
microcapus & & & \\
\hline
\end{tabular}

\section{Healthy Properties}

Mushrooms have been traditionally employed as medicinal agents due to their proven healthy properties. Among the occurring bioactive compounds, polysaccharides are responsible for a wide range of biological activities, the modulation of the immune system being the most studied. Polysaccharides from mushrooms showing a $\beta$-linkage have demonstrated a boost in the human immune system and the modulation of the immunological response under certain circumstances, thus they are commonly termed biological response modifiers (BRM). As a result of the activation of the host's immune system, these polysaccharides show significant antitumor, antiviral and antimicrobial activity, among other effects.

\subsection{Tumor Therapy}

Polysaccharides from fungi have been widely employed in tumor therapies due to their properties as immunological enhancers. Research studies have demonstrated that polysaccharides isolated from different mushroom genera are capable of providing anti-tumoral activity, for instance, Agaricus, Calocybe, Ganoderma, Grifola, Inonotus, Lentinus, Phellinus, Pholiota, Pleurotus, etc. [74-81] The mitogenic activity of fungal polysaccharides involves several mechanisms, such as the antiproliferation of cancer cells and induction of apoptosis, the regulation of the immune system and the antimetastatic effects. These include the activation of macrophages, T lymphocytes and natural killer cells (NK), which are able to secrete inflammatory mediators and cytokines such as the $\alpha$ tumor necrosis factor (TNF- $\alpha$ ), $\gamma$ interferon (IFN- $\gamma$ ), or $1 \beta$ interleukin (IL-1 $\beta$ ), among others. Polysaccharides can depress the E-selectin protein and gene expressions, which inhibit tumoral cell-to-cell adhesion [74]. Other mechanisms include antiproliferative effects, apoptosis induction, and differentiation of the tumoral cells [80].

Fungal polysaccharides have been widely employed as coadjuvants in tumoral therapies. In this field, lentinan, a $\beta-(1 \rightarrow 3),(1 \rightarrow 6)$-linked polysaccharide from Lentinus edodes, has been used in a combined treatment of patients with advanced or recurrent gastric or colorectal cancer. In a study carried out with 89 patients of stomach cancer, lifespan increased in 80 days when $2 \mathrm{mg}$ of intravenous lentinan per week were used $[82,83]$. Similarly, lifespan increased in 106 days in patients with breast cancer when similar doses of lentinan were employed [84].

In a study carried out with 30 patients of breast cancer, the combination of lentinan with chemoendocrine therapy was more effective than chemoendocrine therapy alone on the improvement of hormonal parameters such as serum levels of estradiol, follicle-stimulating hormone, luteinizing hormone and prolactin. Lentinan seemed to exert a dose-reductive effect on epirubicin (EPIR) therapy 
for breast cancer patients, and that combination therapy of lentinan and low-dose EPIR was more effective for the augmentation of the host defense activity than that of lentinan and high-dose EPIR [85].

A combination of lentinan and interleukin 2 (IL-2) has shown a synergistic effect in the reduction of lung metastasis colony numbers (85\%). Furthermore, 3 of 13 mice given the pre-operative combination treatment achieved complete cure. The cellular mechanism of the antimetastatic activity involved a tumor-associated antigen-specific delayed-type hypersensitivity response. These data suggested that the life-prolonging effect of the combination of lentinan and IL-2 was mediated by antigen-specific $\mathrm{T}$ cells and that the combination of pre- and post-operative therapy with lentinan and IL-2 may be effective to prevent cancer recurrence and metastasis after surgical resection [86].

\subsection{Cardiovascular Disease}

Fungal polysaccharides may be beneficial for protection against cardiovascular diseases and its complications. Edible mushrooms are good candidates to be included in a healthy diet for the prevention of atherosclerosis, due to their high fiber and low fat content. Indeed, the mechanisms of action involve anticoagulation and antiaggregation activity in the blood platelets, resulting in low total triglyceride and lipid levels. Furthermore, the hypocholesterolemic effect can be associated to the antioxidant activity. Administration of black fungus polysaccharides had significantly enhanced myocardium and blood antioxidant enzyme activities and reduced lipid peroxidation levels in high fat mice [16]. Studies with humans revealed that diets rich in $\beta$-glucans decreased the total cholesterol and LDL levels in serum, as well as the visceral fat area and the waist circumference in hypercholesterolemic patients $[87,88]$. At the intestinal level, $\beta$-glucans reduced the absorption of cholesterol and long chain fatty acids and, furthermore, these polysaccharides downregulated the genes involved in lipogenesis and lipid transport [89].

\subsection{Antiviral Activity (HIV)}

Although the present results are promising, there is a dearth of studies involving HIV treatment with polysaccharides from mushrooms. A study was carried out with 88 HIV-positive patients with CD4 levels of 200-500 cells $/ \mathrm{mm}$. The patients were treated with a combination of lentinan from Lentinus edodes and didanosine (ddI). The combination caused significant increases in CD4 levels up to 38 weeks, whereas ddI alone was significant at the 5\% level at 14 weeks [90].

\subsection{Antimicrobial Activity}

The ability of polysaccharides from mushrooms to modulate the immune response makes them potential candidates for combination therapy with Calmette-Guerin bacillus (BCG), or as adjunct for BCG vaccination, especially in high-risk individuals. The combined intranasal application of lentinan (at a dose of $1 \mathrm{mg} / \mathrm{kg}$ ), followed by administration of BCG, produced high level of alveolar macrophage activation. Pre-treatment with lentinan enhanced the local immunohistological response to BCG in lung and reduced the generalized side effects [91]. 


\subsection{Antioxidant Activity}

Oxidative damage is related to the prevalence of a great number of common diseases. Therefore, substances capable of acting as antioxidant agents usually prevent the development of certain diseases. Polysaccharides from different mushrooms showed free radical scavenging activity [92], superoxide radical scavenging activity, reducing properties, lipid peroxidation inhibition, suppression of proliferation and oxidative stress, etc. [93] The activity not only depended on the fungal species but also on the chemical structure and arrangement of the active polysaccharide [75,94-96]. Similarly, mixed carbohydrates, such as polysaccharide-peptide complexes, have also shown a potent antioxidant activity [97].

\subsection{Other Effects}

Besides the biological effects described previously, polysaccharides from mushrooms have attracted much attention due to their behavior as dietary fiber. On the one hand, a diet rich in $\beta$-linked polysaccharides improved the gastrointestinal tract motility and, on the other hand, they seemed to improve insulin resistance in patients with type 2 diabetes [98]. Furthermore, the $\beta$-linked polysaccharides produced a satiating effect and the studies showed a reduced energy intake in volunteers [99].

Finally, polysaccharides have shown other healthy effects, for instance anti-aging effects [100], or hepatoprotective activity [101].

\section{Conclusions}

Mushrooms can be viewed as an important source of bioactive polysaccharides. The most common pattern consists of a $\beta$-linked glucose backbone displaying branches at certain sugar residues; nevertheless, other polysaccharides, such as galactans or mannans, or even polysaccharide-protein complexes can also be found in mushrooms. These carbohydrates have been considered as biological response modifiers due to their ability to enhance the immune system and, therefore, prevent and treat several common diseases and promote health. Cancer, cardiovascular diseases, and viral and bacterial infections are among the most studied diseases treated with polysaccharides from mushrooms and the results show that these bioactive carbohydrates may be successfully used in their treatments.

\section{Acknowledgments}

The authors are grateful to Ministerio de Ciencia e Innovación and INIA (projects RTA2009-00049 and AT07-003) for financial support of this work.

\section{References}

1. Chiron, N.; Michelot, D. Odeurs des champignons: Chimie et rôle dans les interactions biotiques-Une revue. Cryptogam. Mycol. 2005, 26, 299-364.

2. Maga, J.A. Mushroom flavor. J. Agric. Food Chem. 1981, 29, 1-4. 
3. Tsai, S.Y.; Tsai, H.L.; Mau, J.L. Non-volatile taste components of Agaricus blazei, Agrocybe cylindracea and Boletus edulis. Food Chem. 2008, 107, 977-983.

4. Beluhan, S.; Ranogajec, A. Chemical composition and non-volatile components of croatian wild edible mushrooms. Food Chem. 2011, 124, 1076-1082.

5. Manzi, P.; Aguzzi, A.; Pizzoferrato, L. Nutritional value of mushrooms widely consumed in Italy. Food Chem. 2001, 73, 321-325.

6. Manzi, P.; Marconi, S.; Aguzzi, A.; Pizzoferrato, L. Commercial mushrooms: Nutritional quality and effect of cooking. Food Chem. 2004, 84, 201-206.

7. Chang, S.T.; Wasser, S.P. The role of culinary-medicinal mushrooms on human welfare with a pyramid model for human health. Int. J. Med. Mushrooms 2012, 14, 95-134.

8. Bohn, J.A.; BeMiller, J.N. $(1 \rightarrow 3)-\beta$-D-glucans as biological response modifiers: A review of structure-functional activity relationships. Carbohydr. Polym. 1995, 28, 3-14.

9. Da Silva, M.D.C.; Fukuda, E.K.; Vasconcelos, A.F.D.; Dekker, R.F.H.; Matias, A.C.; Monteiro, N.K.; Cardoso, M.S.; Barbosa, A.M.; Silveira, J.L.M.; Sassaki, G.L.; et al. Structural characterization of the cell wall D-glucans isolated from the mycelium of Botryosphaeria rhodina MAMB-05. Carbohydr. Res. 2008, 343, 793-798.

10. Muller, A.; Ensley, H.; Pretus, H.; McNamee, R.; Jones, E.; McLaughlin, E.; Chandley, W.; Browder, W.; Lowman, D.; Williams, D. The application of various protic acids in the extraction of $(1 \rightarrow 3)$ - $\beta$-D-glucan from Saccharomyces cerevisiae. Carbohydr. Res. 1997, 299, 203-208.

11. Lo, T.C.T.; Tsao, H.H.; Wang, A.Y.; Chang, C.A. Pressurized water extraction of polysaccharides as secondary metabolites from Lentinula edodes. J. Agric. Food Chem. 2007, 55, 4196-4201.

12. Santoyo, S.; Plaza, M.; Jaime, L.; Ibanez, E.; Reglero, G.; Senorans, F.J. Pressurized liquid extraction as an alternative process to obtain antiviral agents from the edible microalga Chlorella vulgaris. J. Agric. Food Chem. 2010, 58, 8522-8527.

13. Pereira, C.G.; Meireles, M.A.A. Supercritical fluid extraction of bioactive compounds: Fundamentals, applications and economic perspectives. Food Bioprocess Technol. 2010, 3, 340-372.

14. Fu, Y.-J.; Liu, W.; Zu, Y.-G.; Shi, X.-G.; Liu, Z.-G.; Schwarz, G.; Efferth, T. Breaking the spores of the fungus Ganoderma lucidum by supercritical $\mathrm{CO}_{2}$. Food Chem. 2009, 112, 71-76.

15. Riera, E.; Blanco, A.; Garcia, J.; Benedito, J.; Mulet, A.; Gallego-Juarez, J.A.; Blasco, M. High-power ultrasonic system for the enhancement of mass transfer in supercritical $\mathrm{CO}_{2}$ extraction processes. Ultrasonics 2010, 50, 306-309.

16. Ma, J.; Qiao, Z.; Xiang, X. Optimisation of extraction procedure for black fungus polysaccharides and effect of the polysaccharides on blood lipid and myocardium antioxidant enzymes activities. Carbohydr. Polym. 2011, 84, 1061-1068.

17. Tian, Y.; Zeng, H.; Xu, Z.; Zheng, B.; Lin, Y.; Gan, C.; Lo, Y.M. Ultrasonic-assisted extraction and antioxidant activity of polysaccharides recovered from white button mushroom (Agaricus bisporus). Carbohydr. Polym. 2012, 88, 522-529.

18. Zhang, Z.; Lv, G.; Pan, H.; Shi, L.; Fan, L. Optimization of the microwave-assisted extraction process for polysaccharides in himematsutake (Agaricus blazei Murrill) and evaluation of their antioxidant activities. Food Sci. Technol. Res. 2011, 17, 461-470. 
19. Song, J.-F.; Li, D.-J.; Liu, C.-Q. Response surface analysis of microwave-assisted extraction of polysaccharides from cultured Cordyceps militaris. J. Chem. Technol. Biotechnol. 2009, 84, $1669-1673$.

20. Ru, Q.M.; Zhang, L.R.; Chen, J.D.; Pei, Z.M.; Zheng, H.L. Microwave-assisted extraction and identification of polysaccharide from Lycoris aurea. Chem. Nat. Compd. 2009, 45, 474-477.

21. Dong, J.-Z.; Wang, Z.-C.; Wang, Y. Rapid extraction of polysaccharides from fruits of Lycium barbarum L. J. Food Biochem. 2011, 35, 1047-1057.

22. Huang, S.-Q.; Ning, Z.-X. Extraction of polysaccharide from Ganoderma lucidum and its immune enhancement activity. Int. J. Biol. Macromol. 2010, 47, 336-341.

23. Chen, Y.; Gu, X.; Huang, S.-Q.; Li, J.; Wang, X.; Tang, J. Optimization of ultrasonic/microwave assisted extraction (UMAE) of polysaccharides from Inonotus obliquus and evaluation of its anti-tumor activities. Int. J. Biol. Macromol. 2010, 46, 429-435.

24. Palacios, I.; Lozano, M.; Moro, C.; D’Arrigo, M.; Rostagno, M.A.; Martínez, J.A.; García-Lafuente, A.; Guillamón, E.; Villares, A. Antioxidant properties of phenolic compounds occurring in edible mushrooms. Food Chem. 2011, 128, 674-678.

25. Park, H.G.; Shim, Y.Y.; Choi, S.O.; Park, W.M. New method development for nanoparticle extraction of water-soluble $\beta$-( $(1 \rightarrow 3)$-D-glucan from edible mushrooms, Sparassis crispa and Phellinus linteus. J. Agric. Food Chem. 2009, 57, 2147-2154.

26. Ragaee, S.M.; Wood, P.J.; Wang, Q.; Tosh, S.M.; Brummer, Y.; Huang, X. Isolation, fractionation, and structural characteristics of alkali-extractable beta-glucan from rye whole meal. Cereal Chem. 2008, 85, 289-294.

27. Li, W.; Cui, S.W.; Kakuda, Y. Extraction, fractionation, structural and physical characterization of wheat $\beta$-D-glucans. Carbohydr. Polym. 2006, 63, 408-416.

28. Bao, X.F.; Fang, J.N.; Li, X.Y. Structural characterization and immunomodulating activity of a complex glucan from spores of Ganoderma lucidum. Biosci. Biotechnol. Biochem. 2001, 65, 2384-2391.

29. Ye, L.B.; Zhang, J.S.; Yang, Y.; Zhou, S.A.; Liu, Y.F.; Tang, Q.L.; Du, X.J.; Chen, H.; Pan, Y.J. Structural characterisation of a heteropolysaccharide by NMR spectra. Food Chem. 2009, 112, 962-966.

30. Johansson, L.; Virkki, L.; Anttila, H.; Esselstrom, H.; Tuomainen, P.; Sontag-Strohm, T. Hydrolysis of beta-glucan. Food Chem. 2006, 97, 71-79.

31. Blakeney, A.B.; Harris, P.J.; Henry, R.J.; Stone, B.A. A simple and rapid preparation of alditol acetates for monosaccharide analysis. Carbohydr. Res. 1983, 113, 291-299.

32. Bernardo, D.; Mendoza, C.G.; Calonje, M.; Novaes-Ledieu, M. Chemical analysis of the lamella walls of Agaricus bisporus fruit bodies. Curr. Microbiol. 1999, 38, 364-367.

33. Ciucanu, I. Per-O-methylation reaction for structural analysis of carbohydrates by mass spectrometry. Anal. Chim. Acta 2006, 576, 147-155.

34. Agrawal, P.K. NMR spectroscopy in the structural elucidation of oligosaccharides and glycosides. Phytochemistry 1992, 31, 3307-3330.

35. Laws, A.P.; Chadha, M.J.; Chacon-Romero, M.; Marshall, V.M.; Maqsood, M. Determination of the structure and molecular weights of the exopolysaccharide produced by Lactobacillus acidophilus 5e2 when grown on different carbon feeds. Carbohydr. Res. 2008, 343, 301-307. 
36. Wang, L.; Zhang, H.B.; Zhang, X.Y.; Chen, Z.X. Purification and identification of a novel heteropolysaccharide RBPS2a with anti-complementary activity from defatted rice bran. Food Chem. 2008, 110, 150-155.

37. Calonje, M.; García Mendoza, C.; Perez Cabo, A.; Novaes-Ledieu, M. New contributions to the wall polysaccharide structure of the vegetative mycelium and fruit body cell walls of Agaricus bisporus. Microbiología 1996, 12, 599-606.

38. Lee, J.S.; Kwon, J.S.; Won, D.P.; Lee, K.E.; Shin, W.C.; Hong, E.K. Study on macrophage activation and structural characteristics of purified polysaccharide from the liquid culture broth of Cordyceps militaris. Carbohydr. Polym. 2010, 82, 982-988.

39. Yoshioka, Y.; Uehara, N.; Saito, H. Conformation-dependent change in antitumor-activity of linear and branched $(1 \rightarrow 3)$-beta-D-glucans on the basis of conformational elucidation by C-13 Nuclear Magnetic Resonance spectroscopy. Chem. Pharm. Bull. 1992, 40, 1221-1226.

40. Kulicke, W.M.; Lettau, A.I.; Thielking, H. Correlation between immunological activity, molar mass, and molecular structure of different $(1 \rightarrow 3)$-beta-D-glucans. Carbohydr. Res. 1997, 297, $135-143$.

41. Jelsma, J.; Kreger, D.R. Ultrastructural observations on $(1 \rightarrow 3)$-beta-D-glucan from fungal cell-walls. Carbohydr. Res. 1975, 43, 200-203.

42. Sweeley, C.C.; Nunez, H.A. Structural analysis of glycoconjugates by mass spectrometry and nuclear magnetic resonance spectroscopy. Annu. Rev. Biochem. 1985, 54, 765-801.

43. Young, S.H.; Jacobs, R.R. Sodium hydroxide-induced conformational change in schizophyllan detected by the fluorescence dye, aniline blue. Carbohydr. Res. 1998, 310, 91-99.

44. Ko, Y.T.; Lin, Y.L. 1,3-beta-glucan quantification by a fluorescence microassay and analysis of its distribution in foods. J. Agric. Food Chem. 2004, 52, 3313-3318.

45. Ogawa, K.; Dohmaru, T.; Yui, T. Dependence of complex-formation of (1 $\rightarrow 3)$-beta-D-glucan with congo red on temperature in alkaline-solutions. Biosci. Biotechnol. Biochem. 1994, 58, 1870-1872.

46. Dore, C.; Azevedo, T.C.G.; de Souza, M.C.R.; Rego, L.A.; de Dantas, J.C.M.; Silva, F.R.F.; Rocha, H.A.O.; Basela, I.G.; Leite, E.L. Antiinflammatory, antioxidant and cytotoxic actions of beta-glucan-rich extract from Geastrum saecatum mushroom. Int. Immunopharmacol. 2007, 7, 1160-1169.

47. Smiderle, F.R.; Carbonero, E.R.; Sassaki, G.L.; Gorin, P.A.J.; Iacomini, M. Characterization of a heterogalactan: Some nutritional values of the edible mushroom Flammulina velutipes. Food Chem. 2008, 108, 329-333.

48. Numata, M.; Tamesue, S.; Fujisawa, T.; Haraguchi, S.; Hasegawa, T.; Bae, A.H.; Li, C.; Sakurai, K.; Shinkai, S. Beta-1,3-glucan polysaccharide (schizophyllan) acting as a one-dimensional host for creating supramolecular dye assemblies. Org. Lett. 2006, 8, 5533-5536.

49. Chakraborty, I.; Mondal, S.; Rout, D.; Islam, S.S. A water-insoluble (1 $\rightarrow 3)$-beta-D-glucan from the alkaline extract of an edible mushroom Termitomyces eurhizus. Carbohydr. Res. 2006, 341, 2990-2993.

50. Chandra, K.; Ghosh, K.; Roy, S.K.; Mondal, S.; Maiti, D.; Ojha, A.K.; Das, D.; Islam, S.S. A water-soluble glucan isolated from an edible mushroom Termitomyces microcapus. Carbohydr. Res. 2007, 342, 2484-2489. 
51. Dong, Q.; Jia, L.M.; Fang, J.N. A beta-D-glucan isolated from the fruiting bodies of Hericium erinaceus and its aqueous conformation. Carbohydr. Res. 2006, 341, 791-795.

52. Jia, L.M.; Liu, L.; Dong, Q.; Fang, J.N. Structural investigation of a novel rhamnoglucocalactan isolated from the fruiting bodies of the fungus Hericium erinaceus. Carbohydr. Res. 2004, 339, 2667-2671.

53. Wang, J.G.; Zhang, L. Structure and chain conformation of five water-soluble derivatives of a beta-D-glucan isolated from Ganoderma lucidum. Carbohydr. Res. 2009, 344, 105-112.

54. Dong, Q.; Wang, Y.; Shi, L.; Yao, J.; Li, J.; Ma, F.; Ding, K. A novel water-soluble beta-D-glucan isolated from the spores of Ganoderma lucidum. Carbohydr. Res. 2012, 353, 100-105.

55. Bao, X.F.; Wang, X.S.; Dong, Q.; Fang, J.N.; Li, X.Y. Structural features of immunologically active polysaccharides from Ganoderma lucidum. Phytochemistry 2002, 59, 175-181.

56. Chen, Y.; Xie, M.Y.; Nie, S.P.; Li, C.; Wang, Y.X. Purification, composition analysis and antioxidant activity of a polysaccharide from the fruiting bodies of Ganoderma atrum. Food Chem. 2008, 107, 231-241.

57. Xu, S.; Xu, X.; Zhang, L. Branching structure and chain conformation of water-soluble glucan extracted from Auricularia auricula-judae. J. Agric. Food Chem. 2012, 60, 3498-3506.

58. Nandan, C.K.; Patra, P.; Bhanja, S.K.; Adhikari, B.; Sarkar, R.; Mandal, S.; Islam, S.S. Structural characterization of a water-soluble beta- $(1 \rightarrow 6)$-linked D-glucan isolated from the hot water extract of an edible mushroom, Agaricus bitorquis. Carbohydr. Res. 2008, 343, 3120-3122.

59. Gonzaga, M.L.C.; Ricardo, N.; Heatley, F.; Soares, S.D. Isolation and characterization of polysaccharides from Agaricus blazei Murill. Carbohydr. Polym. 2005, 60, 43-49.

60. Zhang, Y.Y.; Li, S.; Wang, X.H.; Zhang, L.N.; Cheung, P.C.K. Advances in lentinan: Isolation, structure, chain conformation and bioactivities. Food Hydrocoll. 2011, 25, 196-206.

61. Carbonero, E.R.; Gracher, A.H.P.; Komura, D.L.; Marcon, R.; Freitas, C.S.; Baggio, C.H.; Santos, A.R.S.; Torri, G.; Gorin, P.A.J.; Iacomini, M. Lentinus edodes heterogalactan: Antinociceptive and anti-inflammatory effects. Food Chem. 2008, 111, 531-537.

62. Palacios, I.; Guillamón, E.; García-Lafuente, A.; Villares, A. Structural characterization of water-soluble polysaccharides from the fruiting bodies of Lentinus edodes mushrooms. Curr. Nutr. Food Sci. 2012, 8, 234-241.

63. Karacsonyi, S.; Kuniak, L. Polysaccharides of Pleurotus ostreatus-Isolation and structure of pleuran, an alkali-insoluble $\beta$-D-glucan. Carbohydr. Polym. 1994, 24, 107-111.

64. Synytsya, A.; Mickova, K.; Jablonsky, I.; Spevacek, J.; Erban, V.; Kovarikova, E.; Copikova, J. Glucans from fruit bodies of cultivated mushrooms Pleurotus ostreatus and Pleurotus eryngii: Structure and potential prebiotic activity. Carbohydr. Polym. 2009, 76, 548-556.

65. Palacios, I.; García-Lafuente, A.; Guillamón, E.; Villares, A. Novel isolation of water-soluble polysaccharides from the fruiting bodies of Pleurotus ostreatus mushrooms. Carbohydr. Res. 2012, 358, 72-77.

66. Santos-Neves, J.C.; Pereira, M.I.; Carbonero, E.R.; Gracher, A.H.P.; Alquini, G.; Gorin, P.A.J.; Sassaki, G.L.; Iacomini, M. A novel branched alpha beta-glucan isolated from the basidiocarps of the edible mushroom Pleurotus florida. Carbohydr. Polym. 2008, 73, 309-314. 
67. Rout, D.; Mondal, S.; Chakraborty, I.; Islam, S.S. The structure and conformation of a water-insoluble $(1 \rightarrow 3),(1 \rightarrow 6)$-beta-D-glucan from the fruiting bodies of Pleurotus florida. Carbohydr. Res. 2008, 343, 982-987.

68. Carbonero, E.R.; Gracher, A.H.P.; Rosa, M.C.C.; Torri, G.; Sassaki, G.L.; Gorin, P.A.J.; Iacomini, M. Unusual partially 3-O-methylated alpha-galactan from mushrooms of the genus Pleurotus. Phytochemistry 2008, 69, 252-257.

69. Rosado, F.R.; Carbonero, E.R.; Kemmelmeier, C.; Tischer, C.A.; Gorin, P.A.J.; Iacomini, M. A partially 3-O-methylated $(1 \rightarrow 4)$-linked $\alpha$-D-galactan and $\alpha$-D-mannan from Pleurotus ostreatoroseus Sing. FEMS Microbiol. Lett. 2002, 212, 261-265.

70. Mandal, E.K.; Maity, K.; Maity, S.; Gantait, S.K.; Behera, B.; Maiti, T.K.; Sikdar, S.R.; Islam, S.S. Chemical analysis of an immunostimulating $(1 \rightarrow 4)-,(1 \rightarrow 6)$-branched glucan from an edible mushroom, Calocybe indica. Carbohydr. Res. 2012, 347, 172-177.

71. Mandal, S.; Maity, K.K.; Bhunia, S.K.; Dey, B.; Patra, S.; Sikdar, S.R.; Islam, S.S. Chemical analysis of new water-soluble $(1 \rightarrow 6)-, \quad(1 \rightarrow 4)-\alpha, \quad \beta$-glucan and water-insoluble $(1 \rightarrow 3)-$, $(1 \rightarrow 4)-\beta$-glucan (calocyban) from alkaline extract of an edible mushroom, Calocybe indica (Dudh Chattu). Carbohydr. Res. 2010, 345, 2657-2663.

72. Mandal, E.K.; Maity, K.; Maity, S.; Gantait, S.K.; Maiti, S.; Maiti, T.K.; Sikdar, S.R.; Islam, S.S. Structural characterization of an immunoenhancing cytotoxic heteroglycan isolated from an edible mushroom Calocybe indica var. APK2. Carbohydr. Res. 2011, 346, 2237-2243.

73. Chauveau, C.; Talaga, P.; Wieruszeski, J.M.; Strecker, G.; Chavant, L. A water-soluble $\beta$-D-glucan from Boletus erythropus. Phytochemistry 1996, 43, 413-415.

74. Yue, L.; Cui, H.; Li, C.; Lin, Y.; Sun, Y.; Niu, Y.; Wen, X.; Liu, J. A polysaccharide from Agaricus blazei attenuates tumor cell adhesion via inhibiting E-selectin expression. Carbohydr. Polym. 2012, 88, 1326-1333.

75. Hsieh, T.-C.; Wu, J.M. Suppression of proliferation and oxidative stress by extracts of Ganoderma lucidum in the ovarian cancer cell line OVCAR-3. Int. J. Mol. Med. 2011, 28, 1065-1069.

76. Lee, K.H.; Cho, C.H.; Rhee, K.-H. Synergic anti-tumor activity of gamma-irradiated exo-polysaccharide from submerged culture of Grifola frondosa. J. Med. Plants Res. 2011, 5, 2378-2386.

77. Selvi, S.; Umadevi, P.; Murugan, S.; Senapathy, G.J. Anticancer potential evoked by Pleurotus florida and Calocybe indica using $\mathrm{T}_{24}$ urinary bladder cancer cell line. Afr. J. Biotechnol. 2011, 10, 7279-7285.

78. Zhang, L.; Fan, C.; Liu, S.; Zang, Z.; Jiao, L.; Zhang, L. Chemical composition and antitumor activity of polysaccharide from Inonotus obliquus. J. Med. Plants Res. 2011, 5, 1251-1260.

79. Lo, T.C.-T.; Hsu, F.-M.; Chang, C.A.; Cheng, J.C.-H. Branched alpha-(1,4) glucans from Lentinula edodes (L10) in combination with radiation enhance cytotoxic effect on human lung adenocarcinoma through the toll-like receptor 4 mediated induction of THP-1 differentiation/activation. J. Agric. Food Chem. 2011, 59, 11997-12005.

80. Wang, G.; Dong, L.; Zhang, Y.; Ji, Y.; Xiang, W.; Zhao, M. Polysaccharides from Phellinus linteus inhibit cell growth and invasion and induce apoptosis in HepG2 human hepatocellular carcinoma cells. Biologia 2012, 67, 247-254. 
81. Hu, Q.; Wang, H.; Ng, T.B. Isolation and purification of polysaccharides with anti-tumor activity from Pholiota adiposa (Batsch) P. Kumm. (higher Basidiomycetes). Int. J. Med. Mushrooms 2012, 14, 271-284.

82. Chihara, G.; Hamuro, J.; Maeda, Y.Y.; Shiio, T.; Suga, T.; Takasuka, N.; Sasaki, T. Antitumor and metastasis-inhibitory activities of lentinan as an immunomodulator: An overview. Cancer Detect. Prev. 1987, 1, 423-443.

83. Ochiai, T.; Isono, K.; Suzuki, T.; Koide, Y.; Gunji, Y.; Nagata, M.; Ogawa, N. Effect of immunotherapy with lentinan on patients survival and immunological parameters in patients with advanced gastric-cancer-Results of a multicenter randomized controlled-study. Int. J. Immunother. 1992, 8, 161-169.

84. Taguchi, T.; Abe, O.; Enomoto, K.; Kusama, S.; Tomiyama, J.; Tominaga, K.; Ogawa, N. Life-span prolongation effect of lentinan on patients with advanced or recurrent breast-cancer. Int. J. Immunopharmacol. 1982, 4, 271-271.

85. Kosaka, A.; Suga, T.; Yamashita, A. Dose reductive effect of lentinan on the epirubicin therapy for breast cancer patients. Int. J. Immunother. 1995, 11, 143-151.

86. Hamuro, J.; Takatsuki, F.; Suga, T.; Kikuchi, T.; Suzuki, M. Synergistic antimetastatic effects of lentinan and interleukin-2 with preoperative and postoperative treatments. Jpn. J. Cancer Res. 1994, 85, 1288-1297.

87. Shimizu, C.; Kihara, M.; Aoe, S.; Araki, S.; Ito, K.; Hayashi, K.; Watari, J.; Sakata, Y.; Ikegami, S. Effect of high beta-glucan barley on serum cholesterol concentrations and visceral fat area in japanese men-A randomized, double-blinded, placebo-controlled trial. Plant Food Hum. Nutr. 2008, 63, 21-25.

88. Naumann, E.; van Rees, A.B.; Onning, G.; Oste, R.; Wydra, M.; Mensink, R.P. Beta-glucan incorporated into a fruit drink effectively lowers serum LDL-cholesterol concentrations. Am. J. Clin. Nutr. 2006, 83, 601-605.

89. Drozdowski, L.A.; Reimer, R.A.; Temelli, F.; Bell, R.C.; Vasanthan, T.; Thomson, A.B.R. $\beta$-glucan extracts inhibit the in vitro intestinal uptake of long-chain fatty acids and cholesterol and down-regulate genes involved in lipogenesis and lipid transport in rats. J. Nutr. Biochem. 2010, 21, 695-701.

90. Gordon, M.; Guralnik, M.; Kaneko, Y.; Mimura, T.; Goodgame, J.; DeMarzo, C.; Pierce, D.; Baker, M.; Lang, W. A phase II controlled study of a combination of the immune modulator, lentinan, with didanosine (ddi) in HIV patients with CD4 cells of $200-500 / \mathrm{mm}^{3} . J$. Med. 1995, 26, 193-207.

91. Drandarska, I.; Kussovski, V.; Nikolaeva, S.; Markova, N. Combined immunomodulating effects of BCG and lentinan after intranasal application in guinea pigs. Int. Immunopharmacol. 2005, 5, 795-803.

92. Asatiani, M.D.; Elisashvili, V.I.; Wasser, S.P.; Reznick, A.Z.; Nevo, E. Free-radical scavenging activity of submerged mycelium extracts from higher basidiomycetes mushrooms. Biosci. Biotechnol. Biochem. 2007, 71, 3090-3092.

93. Asatiani, M.D.; Elisashvili, V.; Wasser, S.P.; Reznick, A.Z.; Nevo, E. Antioxidant activity of submerged cultured mycelium extracts of higher basidiomycetes mushrooms. Int. J. Med. Mushrooms 2007, 9, 151-158. 
94. Heleno, S.A.; Barros, L.; Martins, A.; Queiroz, M.J.R.P.; Santos-Buelga, C.; Ferreira, I.C.F.R. Phenolic, polysaccharidic, and lipidic fractions of mushrooms from northeastern Portugal: Chemical compounds with antioxidant properties. J. Agric. Food Chem. 2012, 60, 4634-4640.

95. Wang, C.; Chen, Y.; Hu, M.; Ding, J.; Xu, C.; Wang, R. In vitro antioxidant activities of the polysaccharides from Tricholoma lobayense. Int. J. Biol. Macromol. 2012, 50, 534-539.

96. Kao, P.-F.; Wang, S.-H.; Hung, W.-T.; Liao, Y.-H.; Lin, C.-M.; Yang, W.-B. Structural characterization and antioxidative activity of low-molecular-weights $\beta$-1,3-glucan from the residue of extracted Ganoderma lucidum fruiting bodies. J. Biomed. Biotechnol. 2012, doi:10.1155/2012/673764.

97. Li, N.; Li, L.; Fang, J.C.; Wong, J.H.; Ng, T.B.; Jiang, Y.; Wang, C.R.; Zhang, N.Y.; Wen, T.Y.; $\mathrm{Qu}, \mathrm{L} . Y$.; et al. Isolation and identification of a novel polysaccharide-peptide complex with antioxidant, anti-proliferative and hypoglycaemic activities from the abalone mushroom. Biosci. Rep. 2012, 32, 221-228.

98. Liatis, S.; Tsapogas, P.; Chala, E.; Dimosthenopoulos, C.; Kyriakopoulos, K.; Kapantais, E.; Katsilambros, N. The consumption of bread enriched with betaglucan reduces LDL-cholesterol and improves insulin resistance in patients with type 2 diabetes. Diabetes Metab. 2009, 35, 115-120.

99. Barone Lumaga, R.; Azzali, D.; Fogliano, V.; Scalfi, L.; Vitaglione, P. Sugar and dietary fibre composition influence, by different hormonal response, the satiating capacity of a fruit-based and a $\beta$-glucan-enriched beverage. Food Funct. 2012, 3, 67-75.

100. Ye, M.; Chen, W.-X.; Qiu, T.; Yuan, R.-Y.; Ye, Y.-W.; Cai, J.-M. Structural characterisation and anti-ageing activity of extracellular polysaccharide from a strain of Lachnum sp. Food Chem. 2012, 132, 338-343.

101. Velebny, S.; Hrckova, G.; Kogan, G. Impact of treatment with praziquantel, silymarin and/or $\beta$-glucan on pathophysiological markers of liver damage and fibrosis in mice infected with Mesocestoides vogae (Cestoda) tetrathyridia. J. Helminthol. 2008, 82, 211-219.

(C) 2012 by the authors; licensee MDPI, Basel, Switzerland. This article is an open access article distributed under the terms and conditions of the Creative Commons Attribution license (http://creativecommons.org/licenses/by/3.0/). 